\title{
REPENSAR LA IDENTIDAD FEMENINA
}

María Gómez y Patiño

Universidad de Helsinki

mariagp@unizar.es

Recibido: 18-12-2009

Aceptado: 13-04-2010

\section{Resumen}

La mujer ha tenido durante siglos un papel secundario en la vida social y pública de nuestra cultura occidental. Este hecho ha resultado nefasto para la conformación de su identidad. Este artículo pretende reflexionar y responder a algunas preguntas:1) ¿Por qué la identidad femenina ha sido ocultada?; 2) ¿Es la clase social un factor determinante? 3) ¿Era un estado vergonzante ser mujer en el mundo cultural? 4) ¿Subsisten estos tabúes en el siglo XXI? La identificación de la mujer con la vanidad, el pecado o con la sabiduría arcana y peligrosa como constante que, aunque en declive aún persiste en los sectores menos progresistas de nuestra sociedad ocultos bajo el barniz democrático de la modernidad.

Palabras clave: Identidad, género, tabú, pecado, sabiduría, Teoría del Etiquetaje.

\begin{abstract}
For centuries women have played secondary roles in social and public life in our western culture. In fact, it has been dreadful for the conformation of women's identity. This article aims to reflect and respond to some questions such as: 1) Why has women's identity been hidden? 2) Is social class a decisive factor? 3) Was a shame to be a woman in the cultural world? 4) Are these taboos alive in XXI century? Women's identification
\end{abstract}


with vanity, sin, or with arcane and dangerous wisdom as a constant characteristic, though in decline, is still alive for the least progressive sectors of our society covered with the democratic varnish of modernity.

Key words: Identity, gender, taboo, sin, wisdom, Labeling Theory.

\section{Introducción}

Este artículo pretende plantear aquí una serie de interrogantes que son sólo algunos de los que invitan a reflexionar sobre este tema: la identidad femenina en la cultura occidental, su génesis, evolución, e incluso su posible tendencia de cambio, ya que como cualquier aspecto sociológico es un concepto dinámico cuya concreción total no concluye jamás. Cabe preguntarse: 1) ¿Por qué la identidad femenina ha sido ocultada?; 2) ¿La clase social como factor determinante? 3) ¿Era un estado vergonzante ser mujer en el mundo social o cultural? 5) Subsisten estos tabúes en el siglo XXI?

La mujer no sólo ha ocupado siempre un segundo lugar para cuestiones sociales, culturales y públicas sino que ha sido así incluso para cuestiones legales como los sistemas hereditarios e incluso sucesorios, como por ejemplo la ley sálica ${ }^{1}$. En otras ocasiones, cuando se acercó a la escena dramática tuvo que hacerlo con un disfraz masculino. Cuando quiso acceder a la literatura tuvo que esconderse tras seudónimos masculinos, y lo que es aún peor, a veces era ella quien escribía, mientras figuraba como autor su marido u otro hombre. Recuérdese el caso de las esposas de Schlegel como curiosidad. La primera, Carolina Böhmer, y la segunda Dorotea Veit (Gómez y Patiño, 1997), la primera tradujo a Shakespeare y la segunda a MMe. Staël y quien firmaba era él. Se les permitía eso sí, hacer una cultura de salón. Sin abandonar el ámbito doméstico

\footnotetext{
${ }^{1}$ Reminiscencia del pasado, superada en algunos países avanzados, que en España se mantiene y que básicamente no permite reinar a las mujeres.
} 
podían organizar veladas poéticas, literarias o musicales, pero sin salir de su espacio femenino: el hogar.

No son desdeñables las mujeres que acabaron sus días en la hoguera. Ciertamente Juana de Arco ha sido recordada por su santidad y su heroicidad, pero existen infinidad de víctimas femeninas de la Santa Inquisición, condenadas por brujas y sacrificadas en el más oscuro de los anonimatos y de las vergüenzas.

Es sobradamente conocido el gran proverbio español que dice: Detrás de todo gran hombre, hay una gran mujer. Popularmente era este hecho socialmente tan aceptado que incluso los refranes describen a la mujer en segundo plano y han transmitido esta posición secundaria de generación en generación. Al parecer, la mujer había de estar siempre sojuzgada o bajo sospecha en todos los órdenes de la vida. Todavía hoy persiste este prejuicio. Así, cuando una mujer llega a un alto cargo aparece la sospecha. La más generalizada tiene siempre tintes seductores, cuando no claramente sexuales. No sucede lo mismo con el hombre. Si un varón llega a un alto cargo nadie duda de que es por su valía personal, hecho que podría ser cuestionado en algunas ocasiones.

En el siglo XXI, cuando la mujer perteneciente a cualquier clase social puede firmar su obra literaria sin seudónimo, la sospecha sigue estando presente. La pregunta descalificadora es ahora referida a su producción intelectual: si su obra es una literatura femenina, por y para mujeres como si se tratara de un género menor para lectoras inferiores, de capacidad inferior o de un subgénero literario. Todo parece indicar que lo menor ha de ser siempre femenino y masculino lo mayor. Se diría que la mujer parece estar revestida de un halo que enturbia, empequeñece y ennegrece su imagen, tanto a sí misma, como a su producción intelectual. Irónicamente, ese halo no parece conformarse con ennegrecer, sino que produce invisibilidad para las mujeres, haciéndolas invisibles. Es difícil imaginar de qué se trata, e imposible averiguar qué es lo que han de esconder la mujer tras la imagen masculina. Lo cierto es que todas estas circunstancias históricas han ido conformando la identidad femenina, minusvalorada y marginada unas veces, $\mathrm{y}$ temida y sojuzgada, otras. 


\section{Objetivos}

El primer objetivo es por tanto averiguar de qué delito se acusa a la mujer para tener que ocultar su identidad y, en segundo lugar, reflexionar sobre los motivos que conducen a la mujer a plegarse a esta imposición patriarcal, como única vía de conseguir y disfrutar del estatus de ciudadanía, aunque sea tras la figura masculina, dado que aparentemente estos derechos ciudadanos sólo podían ser disfrutados por el varón.

Metodológicamente se realizará un recorrido, no lineal ni continuo dado que no se pretende revisar exhaustivamente la literatura existente, inabarcable por otra parte en un artículo, sino sólo detenerse en grandes etapas históricas, muy representativas, como son el Imperio Romano, la Edad Media y la Modernidad, por lo que, los textos históricos o literarios has sido seleccionados por lo ilustrativo y esclarecedor de su contenido que, en unos casos resultarán explicativos de los atributos utilizados para la mujer, y en otros, justificativos del espacio de confinamiento para ellas creado. Por ello, estos textos clásicos ofrecen distintas respuestas en torno a la formación de opiniones estereotipadas y perpetuadas a lo largo de la historia, clichés éstos transmitidos por algunos de los autores varones más importantes de todas las épocas, que aunque no justifican en absoluto la lógica de la discriminación o de la exclusión, sí ayudan a entender la génesis, la transmisión y la perpetuación de tales ideas. Los modelos de exclusión femenina han ido modificándose de acuerdo con los diferentes contextos sociales o históricos, y en ese sentido, la cultura hispánica ha dado grandes muestras de ello. Ya desde el Imperio Romano, en Hispania, según Martínez (1994:33):

“[...] tras la conquista e influencia romana se consolida una sociedad patriarcal con un modelo político y simbólico que excluía a las mujeres, las silenciaba y las colocaba bajo la potestad del pater. En esta sociedad las mujeres podían ser ciudadanas romanas, pero ello no presuponía su participación en la vida política, aunque sí les permitía disfrutar de otros derechos de carácter privado 
como la propiedad, la herencia, la transmisión de patrimonio, etc. Desde el punto de vista público, la ciudadanía femenina tenía un objetivo único, la reproducción del sistema familiar y social romano, pues era imprescindible que todo ciudadano romano estuviese casado legítimamente, es decir, con una ciudadana, para que formara una familia, y transmitiera tanto sus propiedades como su ciudadanía a sus hijos. El Derecho Romano, era, según esta autora infinitamente más progresista de lo que lo han sido los códigos civiles o penales posteriores".

Lo cierto es que la vida y la existencia bajo esta cultura patriarcal vejatoria no sólo transformaban las relaciones sociales, sino también las propias relaciones personales, e incluso las íntimas. La mujer debía vivir y sobrevivir bajo las condiciones que le eran impuestas, donde su identidad resultaba minusvalorada, cercenada, o simplemente inexistente. La intracomunicación femenina estaba seriamente herida y su autoestima rara vez flotaba en la superficie social.

Esta relación interna, esta intracomunicación, ha ido teniendo expresiones diferentes según épocas, por lo que conviene contemplar la evolución de la misma, y sus razones: políticas, económicas, demográficas, etc. De alguna forma, todas ellas pueden explicarse bajo el auspicio de la Teoría del Etiquetaje (Labelling Theory).

\section{La Teoría del Etiquetaje en la génesis de la identidad femenina}

La Teoría Sociológica del Etiquetaje (Lemert, 1972; Wright, et .al., 2000) permite explicar y entender e interpretar, desde el siglo XXI, algunas de las actuaciones y relaciones hombre-mujer dentro de la cultura patriarcal occidental de siglos pasados. Se trataría de la aplicación de esta teoría en su fase primaria. Si bien todas estas características no han sido probadas para todas las mujeres en todas las condiciones, sí podría afirmarse que su enunciado crea el efecto no deseado de la profecía que se 
cumple irremediablemente, de forma mayoritaria. La teoría viene a explicar cómo si durante un largo e ininterrumpido periodo de tiempo a una persona influenciable se le atribuyen una serie de características (etiquetas), estos atributos, ciertos o no, acaban convirtiéndose en una realidad. Si esto funciona con un niño en edad temprana, muy sensible por tanto a las influencias, sólo con la persistencia de un breve espacio de tiempo, cabe esperar el mismo efecto en las mujeres, igualmente sensibles, que durante siglos han venido cargando con algunas características femeninas, esbozadas ya por el padre de la filosofía y de la ciencia: Aristóteles. Él enunció como verdades incontestables algunos atributos femeninos, cuyas afirmaciones, en función de la fuente de procedencia, no podían ni siquiera ser cuestionadas por autores de su época o posteriores.

María Ángeles Durán (2000: 36), ha cuestionado si no todos, sí algunos de los atributos que adornaban a las mujeres, y que Aristóteles atribuye a las féminas. Entre paréntesis señala la contra-lectura que puede o debe hacerse de estas características:

“ a) celosa (de la conducta libre de otros),

b) quejosa (de los bienes de otros y de los males propios),

c) propensa a engañar y golpear (a ejercer la educación sin autoridad)

d) poco esperanzada (con memoria y capacidad de prever),

e) desprovista de vergüenza o respeto de si misma (destinada a obedecer),

f) falsa de palabra y engañosa (el silencio es su ornato; no se le permite usar la palabra salvo en asuntos menores),

g) le es difícil ponerse en acción (porque depende de autorizaciones y recursos ajenos)".

No se pone en cuestión que existan personas (mujeres y hombres) poseedoras de estos calificativos, pero no deben ser asociados siempre al género femenino, y nunca a todos los miembros del colectivo femenino, ni del masculino. Esto sería tanto como 
decir que todas las mujeres se comportan de acuerdo con el Mito de $E v a^{2}$ y ninguna con el de María. Siendo así que los dos mitos son femeninos, no siempre la imagen de la mujer ha de ir asociada a la veleidad, a la vanidad, a la vileza, sino también a la seriedad, a la prudencia y a la bondad.

\section{Socialización, educación diferenciada y exclusión}

No se puede hablar de identidad femenina sin hablar de la masculina, y en este sentido, como dice Georges Duby (1992: 104-5):

“[...] sería ineficaz separar la historia de la mujer de la del hombre. Es necesario estudiar conjuntamente la evolución de la condición de cada uno de los dos sexos. En la Edad Media es evidente que la condición femenina mejoró, pero la condición masculina también lo hizo; así mismo hay que preguntarse si la diferencia entre una y otra se modificó realmente. Del mismo modo, en el terreno de la vida religiosa, parece que no se puede, por ejemplo, separar la historia de las enclaustradas de la de los enclaustrados, ni la evolución de la mariología o de la relativa a la cristología".

Pero, no es menos cierto que, aunque no deban ser separados para entender una época histórica, la realidad era que los niños eran retirados del universo femenino, para ser integrados en el mundo de los hombres, para no volver prácticamente a salir de él, de una manera brutal en ocasiones. No hay duda de que esta separación y retiro de los niños de sus propias madres, para ser socializados junto a sus padres, o a otros hombres, contribuía a construir dos identidades claramente distintas: la masculina y la femenina.

\footnotetext{
${ }^{2}$ El mito de Eva y de María hace referencia a las figuras bíblicas: Eva como símbolo de la tentación y del pecado, y María como símbolo de la virtud y la bondad.
} 
Grosso modo, con algunas excepciones, la educación y la socialización de las mujeres ha sido distinta y separada de los hombres a lo largo de la historia. En España, salvando algunos paréntesis históricos como el periodo republicano previo a la guerra civil española (1936-39), no ha sido hasta la democracia (1975) que niños y niñas han empezado a ser educados juntos. Anteriormente, o estaban en aulas separadas o en centros educativos distintos. La identidad femenina se iba forjando de forma distinta y distante de la masculina, lo que condicionaba su propia personalidad e identidad y sus relaciones sociales. Las posibilidades de acceso a la educación superior para la mujer fueron casi inexistentes lo que significó su ausencia del ámbito laboral, social y público, lo que no impedía que, además de excluida fuera también temida, dado que el temor y la exclusión suelen ser dos caras de una misma moneda, o si se prefiere ésta consecuencia de aquélla.

Existe un poder femenino rival del poder de los hombres, que en buena medida persiste hasta nuestros días, presente tanto en el ámbito laboral como doméstico. Según Duby (1992:105) el espacio doméstico puede ser considerado como el campo de un conflicto $^{3}$ permanente, de una lucha de sexos:

"Este conflicto interno determina esta actitud de miedo que es uno de los principales componentes de la psicología masculina ${ }^{4}$. Miedo ante la mujer, y en particular ante la propia mujer, miedo a ser incapaz de satisfacer a ese ser que se supone devorador pero también portador de muerte, utilizando como los seres débiles armas perversas: venenos, sortilegios. Esta inquietud es superada mediante el desprecio de la mujer, que, sin embargo, no es disociable de otro sentimiento: la nostalgia del seno materno. Si anteriormente se hablaba de estos niños que a la edad de siete años eran separados brutalmente de su madre, arrancados del universo femenino en el que habían sido incubados, el análisis

\footnotetext{
${ }^{3}$ Este campo de conflicto doméstico, no comentado en el texto, podría explicar algunas de las violencias domésticas ejercidas contra la mujer.

${ }^{4}$ Esta cursiva es añadida para destacar su pertinencia.
} 
de ciertas biografías, la del monje Guibert de Nogent, por ejemplo, muestra que los hombres difícilmente superaban este trauma, cuya impronta regía durante toda su vida algunas de sus actitudes fundamentales respecto a las mujeres. El gran dilema es si la mujer era simplemente considerada inservible o temible. Cualquiera respuesta adoptada, la realidad es que sus valores eran negados”.

Se rechazaba a la mujer por inservible en unas ocasiones y se negaban sus valores en otras, por miedo quizá a esa sabiduría arcaica y arcana, en ocasiones funesta para ella por ser perseguida hasta la hoguera, por ejemplo, pero siempre era excluida y marginada.

Las exclusiones, marginaciones, expulsiones o distintas formas de cierres sociales, no suelen ser procesos inocentes. Están cargados de intenciones interesadas para alejar aquello que se teme, en este caso a la mujer y a su sabiduría, a sus valores.

\section{Negación de los valores femeninos}

Dado que los valores dominantes han sido tradicionalmente masculinos, no cabía esperar otra cosa en una cultura patriarcal. Este hecho explica en parte la resistencia de un sector de mujeres que todavía hoy se niega a aceptar su propia identidad femenina, e intentan, en cambio, imitar las pautas de comportamiento dominantes, las masculinas. El mismo Fray Luis de León (1942), cuando en La Perfecta Casada ${ }^{5}$ habla de valor de la mujer, lo que él define como "mujer de valor" es sinónimo de "mujer varonil", es decir, se ve adornada con cualidades propias del hombre: virtud de ánimo, fortaleza de corazón; industria y riquezas; además de poder y aventajamiento. Es la posesión de estas cualidades masculina lo que hace superior a la mujer. Luego, no es valor en cuanto a mujer, sino en cuanto se asemeja al hombre. Es decir, cuanto más

\footnotetext{
${ }^{5}$ Cap. 2, p. 58.
} 
se asemeje la mujer al hombre, tanto más valiosa será. Él adjudica, como propia, la honestidad a la mujer:

\begin{abstract}
"Ser honesta una mujer (...) es como el ser y la substancia de la casada, porque si no tiene esto, no es ya mujer, sino alevosa ramera y vilísimo cieno, y basura la más hedionda de todas y la más despreciada". Idea que repite: "a la buen ay honesta la naturaleza no la hizo (...) sino para un solo oficio simple y doméstico" (Fray Luis de León, 1942: 164).
\end{abstract}

Tales palabras, como ramera, cieno y basura hedionda, resultan claramente ofensivas para los oídos de cualquier mujer y resultan más que impropias para un fraile que aspiraba a la santidad. Con bondad y generosidad hacia la interpretación de la historia, quizá le pueda llegar a perdonar esta palabras a un agustino del siglo XVI, pero lo inaceptable en el siglo XXI es que estos valores tengan que ser exclusivamente masculinos, por "varoniles", de la misma forma que no parece aceptable pensar que los sentimientos sean exclusivamente femeninos, por "sensibles". La igualdad pasa necesariamente por aceptar que ambos géneros son capaces de mostrar energía y fortaleza en ocasiones, y sensibilidad y delicadeza, en otras.

En lo relativo a las cualidades propias del hombre, para Fray Luis de León, como la virtud de ánimo, fortaleza de corazón; industria y riquezas; además de poder y “aventajamiento". Resulta muy interesante ver la evolución de esta última virtud. Sería muy oportuno preguntarse si, a lo largo de la historia social, se ha podido pasar de "aventajamiento" a "ventajismo". Si así fuera, es difícil encontrar un término que resulte más opuesto a la igualdad que éste, y que justificaría la distancia social entre hombre y mujer; explicaría la discriminación. Porque ¿cuál ha sido originaria y tradicionalmente la función social de la mujer? El hecho de que las mujeres no formasen parte del poder político oficial no las excluía de las tareas productivas. Eso es lo que afirma Cándida

\footnotetext{
${ }^{6}$ Cap. 12 .
} 
Martínez (1994), al exponer que las actividades realizadas por las mujeres eran básicas en el mantenimiento del sistema económico, ya que preparaban y arreglaban los instrumentos de trabajo, preparando recipientes, conservando los frutos, cuidándolos a lo largo de los meses; fabricando el vino y el aceite, confeccionando los vestidos, elaborando el alimento cotidiano. La precaria organización de la producción y el trabajo estaban basados en una falsa complementariedad, donde las mujeres, libres o esclavas, desempeñaban actividades no valoradas, pero fundamentales en el conjunto de la producción ${ }^{7}$.

Una vertiente particular de la mujer en esta actividad productora era la de constituir la mano de obra, mientras que la gestión y dirección del proceso estaba en manos de los varones. Era a través del vínculo marital o parental como se reproducía esta situación. Tanto ese vínculo como la posición de dominio venían reforzados por la posición pública y política de los varones.

En el seno del grupo doméstico, por ejemplo, había distribución de roles. Mientras que los hombres tenían a su cargo la actividad exterior, social y pública; las mujeres normalmente se encontraban confinadas en el interior, en esa habitación que era, en el corazón de la casa, como una matriz, y que no pocos autores han identificado con la cocina ${ }^{8}$. En esta interioridad reconocemos lo que era la función femenina esencial: la procreación, pero también el gobierno de los secretos más misteriosos de la vida, que afectan al nacimiento y a la muerte, ya que eran las mujeres las que procedían a lavar los cuerpos de los recién nacidos y, también, los cadáveres de los difuntos. El interior de la casa asimismo, se correspondía natural y metafóricamente con el cuerpo femenino. Finalmente, tanto trabajadoras como reproductoras de mano de obra o del cuerpo cívico, como grandes propietarias o pequeñas campesinas provincianas, las

\footnotetext{
${ }^{7}$ Todavía hoy las mujeres son utilizadas como agente productivo, sin que se valore su actividad o se inscriba dentro de los distintos regímenes de seguridad tanto autónoma como por cuenta ajena, especialmente en áreas rurales.

${ }^{8}$ No puede olvidarse que el lema $K-K-K$ (Kuche, Kinder, Kirche) (Cocina-Hijos-Iglesia) está todavía hoy vigente en muchas de las mentalidades demócrata-cristianas con lo que, producción, reproducción y religión son tres vocablos plenamente actuales.
} 
mujeres del pasado estuvieron privadas de la proyección política que les permitiera hacer valer sus intereses y derechos, (excepciones hechas de su pertenencia a una clase social alta). Su espacio era el doméstico. Es este dominio interior secular el que ha hecho que la identidad femenina se sienta más cómoda en lo íntimo, en las distancias cortas, e incluso en los ambientes donde los sentimientos y las emociones se manifiestan de forma privada.

\section{Algunos textos significativos}

La utilización de los textos histórico-literarios como herramienta metodológica permite confrontar una realidad social pasada (Lukacs, 1916; Goldmann, 1967) desde la perspectiva sociológica presente. La literatura suministra infinitos ejemplos de desigualdad, de exclusión y de desprecio mostrado hacia ese ser inferior-superior que es la mujer, y que iban generando su identidad. Para ello, han sido seleccionados dos: uno de índole negativa contra la mujer, escrita por un hombre, y otro positivo, escrito por una mujer; Baltasar Gracián y Emilia Pardo Bazán, respectivamente. El primero, citado por Ma Antonia Bel (2000:61) es:

"Más vale la maldad del varón que el bien de la mujer, dijo, porque menos mal te hará un hombre que te siga. Mas no es un enemigo solo, sino todos en uno, que todos han hecho plaza de armas en ella: de carne se compone, para descomponerle; el mundo la viste; para poder vencerle a él, se hizo mundo della, y la del mundo se viste, del demonio se reviste en sus engañosas caricias. De aquí sin duda, procedió el apellidarse todos los males hembras... hacénle la guerra al hombre diferentes tentaciones en sus edades diferentes; unas de mocedad y otras en la vejez, pero la mujer en todas. Nunca está seguro de ellas, ni mozo, ni varón ni sabio, ni valiente, si santo; siempre está tocando 
el arma este enemigo común y tan casero” (Baltasar Gracián, El Criticón, Madrid, 1657).

Obviamente, no se puede hacer una interpretación desde el siglo XXI de un texto del siglo XVII, porque hoy resultaría más que un texto de carácter preventivo, un texto de carácter cómico, quasi-bufo, que no hace sino conseguir la ironía generalizada: La mujer como enemigo común y casero de cualquier hombre.

Diametralmente opuesto resultan los textos escritos por una mujer, del siglo XIX. De hecho, el primer texto, las cartas que Emilia Pardo Bazán dirige a Gertrudis Gómez de Avellaneda constituyen la mejor vía de aproximación al talante de la escritora en este momento, que no manifiesta asomo alguno de victimismo, aunque sí traduce una clara conciencia de ser objeto de un atropello por el único motivo de ser mujer. En estas cartas, doña Emilia quiere dejar constancia de que el hombre y la mujer deben tener los mismos derechos y pueden expresarse de idéntica manera. Comienza por manifestar que no cree que la mujer deba disculparse -como era bastante usual- por aparecer en el ámbito público; piensa muy al contrario que tiene derecho a ello y que hay que valorar que sea capaz de manifestar "el propio valer cuando se funda en verdaderos méritos" (Pardo Bazán, 1999:31). El segundo texto es:

"La distancia social entre los dos sexos es hoy mayor que era en la España antigua, porque el hombre ha ganado derechos y franquicias que la mujer no comparte. Suponed a dos personas en un mismo punto; haced que la una avance y que la otra permanezca inmóvil; todo lo que avance la primera, se queda atrás la segunda. Cada nueva conquista del hombre en el terreno de las libertades políticas, ahonda el abismo moral que se separa de la mujer, y hace el papel de ésta más pasivo y enigmático. Libertad de enseñanza, libertad de cultos, derecho de reunión, sufragio, parlamentarismo, sirven para que media sociedad (la masculina) gane fuerzas y actividades a expensas de la otra media femenina. Hoy ninguna mujer de España -empezando por la que ocupa el 
trono- goza de verdadera influencia política; y en otras cuestiones no menos graves, el pensamiento femenino tiende a ajustarse fielmente a las ideas sugeridas por el viril, el único fuerte. A fin de demostrar la exactitud de este aserto, me bastará analizar un solo aspecto del alma femenina en España: el aspecto religioso. Ya dejo dicho que en mi patria, lejos de aspirar el hombre a que la mujer sienta y piense como él, le place que viva una vida psíquica cerebral, no sólo inferior, sino enteramente diversa. La mujer española es creyente por instinto, no lo niego, pero ayuda mucho al desarrollo de ese instinto la ley, promulgada por los hombres de que sus hijas, hermanas, esposas y madres no pueden ser ni son más que acendradas católicas” (Pardo Bazán, 1999: 89).

Estas prácticas, vigentes en el siglo XIX tal como lo describe doña Emilia, ya existían desde la más temprana Hispania romana, tal como refleja Cándida Martínez (1994: 38), al menos:

“[...] las mujeres encontraban en la religión una de las vías para proyectarse en la vida social de la ciudad, y en sus diosas y dioses los resortes ideológicos para reproducir o cambiar los comportamiento morales establecidos, obtener satisfacciones personales, ayuda, etc. Las mujeres, solteras y casadas, cumplían una misión importante en la reproducción del orden establecido: su participación en acciones suplicatorias a los dioses, en procesiones de acción de gracias, en ceremonias expiatorias frente a los prodigios, por la pervivencia y el bien de la ciudad tenía un profundo significado. Esta intensa participación en la vida religiosa y su proyección social explica el activo comportamiento de las mujeres en los comienzos del cristianismo, tanto en los movimientos oficiales como en los heréticos". 
Resulta muy evidente que en el universo de la religión, las mujeres tenían un espacio sólo como agentes pasivos nunca como agentes activos. Aún así, este universo estaba abierto a las mujeres, prácticamente como único reducto donde acudir sin ser excluidas. Pero lo más sorprendente es que este hecho, que ya era válido en la Hispania romana lo siguiera siendo en la España del siglo XIX, tal como Emilia Pardo Bazán (1999: 79-80) cuenta en las cartas citadas, donde narraba el rechazo de su candidatura a un sillón de la Academia, haciendo mofa de la argumentación de los académicos para su rechazo, incluso a la misma Santa Teresa de Ávila si esta hubiera llamado con su báculo a las puertas de la Academia Española:

“Señora Cepeda, su pretensión de usted es inaudita. Usted podrá llegar a ser el dechado del habla castellana, porque eso no lo repartimos nosotros; bueno; usted subirá a los altares, porque allí no se distingue de sexos: corriente; usted tendrá una butaca de oro en el cielo, merced a cierto lamentable espíritu demagógico y emancipador que aflige a la Iglesia: concedido; ¿Pero sillón aquí? Vade retro, señora Cepeda. Mal podríamos, estando usted delante, recrearnos con ciertos chascarrillos un poco picantes y muy salados que a última hora nos cuenta un académico (el cual lo parla casi tan bien como usted, y es tan adversario del naturalismo). En las tertulias de hombres solos no hay nada más fastidioso que una señora, y usted, doña Teresa, nos importunaría asaz."

Esta exclusión, forjada día a día, año a año, siglo a siglo, durante veinte largos siglos puede generar un gran dolor. Obsérvese que esa es al menos el sentimiento de doña Emilia, que por una cuestión de dignidad humana, que no sólo femenina. No iba a empezar una guerra contra eso por no parecer una Académica desairada. Aunque habría tenido sobradas razones para hacerlo. Pues bien, ese dolor, este menosprecio, es precisamente el mismo que de una forma tajante establece y define Celia Amorós (1996: 164): 
“[...] el problema moral de nuestro tiempo es la cantidad de sufrimiento generado por la opresión de las mujeres en las sociedades patriarcales. Parte de la asunción del principio utilitarista-hedonista de que el fundamento de la moralidad estriba en la consecución de la mayor felicidad para el mayor número, articulando desde el mismo la propuesta de una ética feminista del interés que deberá servir de base a la "evolución cultural de la vida cotidiana".

Es más que aceptable la afirmación de Celia Amorós, sobre la necesidad de articular una ética feminista, lo cierto es que como paso previo, la identidad femenina debería ser repensada. La autoestima destruida durante siglos va a necesitar de un gran esfuerzo sobre todo femenino, donde efectivamente la base de una ética feminista puede ayudar a la evolución cultural de la vida cotidiana, para hombres y mujeres.

\section{Conciencia e identidad femenina sin valor carencial freudiano}

La identidad femenina ha de ser repensada y reconstruida. En la actualidad todavía se hacen muchas interpretaciones freudianas sobre las carencias femeninas que, cuando menos, resultan anacrónicas. Se ha de hacer una valoración desde la perspectiva femenina de estas “carencias" freudianas. Rita Ma . Radl (1996:16) señala como indicación que "se debe hacer una valoración de carencia a la identidad del género femenino, en relación con la identidad masculina, pretendiendo, o no, "igualar" la identidad femenina a la masculina". Es muy posible que esta valoración aproximaría el enfoque teórico freudiano sobre la constitución de las identidades sexuales masculina y femenina, pero en la actualidad este modelo freudiano ya no puede ser el enfoque, dado que el proceso moderno de la división social del trabajo y el consiguiente aumento de la segregación de las tareas sociales otorgan un significado de verticalidad a las relaciones de género. Necesariamente se tienen que incorporar las modificaciones que provienen 
de un reconocimiento de las diferencias inherentes a las funciones e identidades colectivamente tradicionales de mujeres y varones, absolutamente básicos, por otra parte, para la existencia y vida humana en su conjunto.

Dicho de otro modo, el enfoque teórico del Psicoanálisis que asume la teoría social moderna en el sentido freudiano ortodoxo, ofrece en virtud de su propio constructo conceptual las categorías teóricas para comprender el proceso de la constitución de las identidades de género en términos sociológicos, esto es, como un proceso históricamente generado que en sí es variable y modificable. La experiencia empírico-social demuestra además que las modificaciones emergen de las interacciones activas de los propios sujetos. Bourdieu (1998) ya planteó cómo las mujeres víctimas de la dominación masculina podrían aceptar inconscientemente su carencia freudiana y como ese inconsciente antropocéntrico sobrevive actualmente.

Aunque es difícil determinar cuándo nació en las mujeres su conciencia feminista, según Solé (1988:80), "puede que ésta fuera desarrollándose en proporción a las marginaciones sufridas por ellas. Se vieron convertidas en elementos subordinados al hombre y fueron conscientes de que la desigualad sería su presente y su futuro".

En España, a lo largo del siglo XIX y primera mitad del XX si bien no hubo movimientos feministas organizados como en los países anglosajones, sí se dio la penetración de las ideas feministas, así como su arraigo y débil desarrollo, que se tradujo en una activación de las tareas en pro de los derechos de la mujer. No se intentó en ningún aso socavar los cimientos de la sociedad establecida con la excepción del periodo de la guerra civil. Se trató más de reformar que de igualar. De ningún modo se puso en discusión el papel tradicional de esposa y madre, pero se logró la contemporización con las nuevas ideas llegadas al país.

Las mujeres españolas crearon numerosas asociaciones, aunque éstas estaban carentes de agresividad. El feminismo español llegó tarde, cuando ya había perdido combatividad tras la Primera Guerra Mundial y no se encontró con las mismas circunstancias socioeconómicas que en los países anglosajones y esto ha marcado desfavorablemente su desarrollo posterior. La sociedad española en general no acepta 
fácilmente los “ismos" y el feminismo quizá menos aún que otros. Se llega a la paradoja de que gran parte de la sociedad española está a favor de la igualdad como derecho humano fundamental mientras que muestra algún rechazo hacia el feminismo, que es, en esencia, lo mismo.

\section{Excepciones históricas basadas en su clase social}

No se debería pasar por alto el hecho de que la clase social ha sido siempre un factor determinante para la aceptación o el rechazo social. La monarquía, la nobleza o las clases sociales más altas siempre han gozado de privilegios exclusivos de los que no gozaban las clases sociales más bajas, y este hecho también era de aplicación para las mujeres como parte de esas clases. Dicho de otra forma, lo que no se aceptaba en las clases sociales bajas sí se aceptaba en las altas. Existen algunas excepciones que permitían brillar a la mujer con luz propia: su palabra y su nombre. A modo de ejemplo y puntualmente, existen casos destacables en la Edad Media como el de María de Francia, que escribió con su propio nombre los maravillosos lais $^{9}$ y otros escritos, hija posiblemente de Leonor de Aquitania, entre las reinas, o Hildegard von Bingen o Elisabeth von Schönau, entre las monjas de clase alta que escribían con su nombre, sin seudónimo alguno en el siglo XII, en Francia y Alemania respectivamente. En el siglo XIX las mujeres socialmente acomodadas ya podían celebrar sus propios salones culturales en el hogar y algunas intelectuales, (Pardo Bazán, 1999) ya empezaban a destacar tanto en la esfera social como en la pública. Caso aparte los constituyen algunas circunstancias excepcionales, cual es el papel de la mujer a lo largo de la

\footnotetext{
${ }^{9}$ Una serie de poemas narrativos cortos escritos en anglo-normando hablaban de historia de amor o aventuras de algún héroe.
} 
historia en momentos de crisis social. Conviene destacar que es precisamente en estas ocasiones cuando el cambio social se ha producido de una manera más poderosa, si bien transitoria y circunstancialmente.

En este mismo sentido, (Martínez, 1994: 33) sostiene que "el proceso de desaparición de la tutela, y la mayor presencia y libertad de las mujeres obedeció a circunstancias históricas relacionadas con la crisis de los modelos, económicos o políticos, fruto de la propia evolución de la sociedad romana”. Una vez más los modelos romanos más clásicos siguen teniendo vigencia para la comprensión y la interpretación de nuestra sociedad, que, en momentos puntuales o críticos, donde la ausencia del hombre o de una identidad masculina en el panorama social cotidiano, obliga a la mujer a ocupar su puesto, transformando así su identidad. Por aproximación a la aplicación del Principio de Heisenberg, una vez modificada una situación ya nunca vuelve a ser igual, pese a que las circunstancias iniciales vuelvan a ser similares.

El ejemplo más claro lo constituye la guerra: cuando el hombre abandonaba el hogar durante un tiempo, en su ausencia la mujer ocupaba su lugar y se hacía cargo de todas las responsabilidades, tanto las de una $\mathrm{u}$ otra identidad. Cuando la paz se restablecía y el hombre volvía a su hogar, la mujer volvía a ocupar su rol femenino, pero ya no exactamente igual que lo había dejado. Se habían producido cambios en su personalidad y en su identidad. Esta razón, de hecho, ya ha venido siendo utilizada para explicar las razones por las que las mujeres nórdicas de hoy, las finlandesas, suecas y noruegas sobre todo, tienen mayores derechos y un más alto grado de conciencia igualitaria que las mujeres mediterráneas, por ejemplo.

La explicación viene dada por la tradición nórdica, donde los hombres eran cazadores y pescadores, además de guerreros, por lo que pasaban largas temporadas del año fuera del hogar, y eran precisamente las mujeres las que desarrollaban el rol masculino y por tanto su identidad evolucionó también de una forma distinta y más rápida hacia la igualdad, hacia una identidad femenina paritaria. Identidad ésta que estaba reforzada por la propia transformación de los roles masculinos a su vuelta al hogar. Hay que pensar que a su regreso se debía producir una readaptación de ambos 
roles, hasta que ambos encontraban su comodidad identitaria. Es decir, al cambiar el rol y la identidad femenina, también cambiaba el rol y la identidad masculina y ambos caminaban hacia una situación más igualitaria, definitivamente paritaria.

\section{A modo de conclusión}

La ocultación de la identidad femenina tras la masculina viene explicada en buena medida por la Teoría del Etiquetaje. No se puede olvidar que este rol secundario socialmente impuesto por una sociedad patriarcal fue forjando una identidad femenina sometida, silenciada y sojuzgada que poco a poco ha ido transformándose en función de los diferentes momentos y avatares históricos, especialmente en momentos de ausencia masculina (debido a causas como guerras, caza, pesca u otras). Sería deseable por tanto que, si la mujer ha podido formar parte activa del proceso social en momentos críticos en la historia, es deseable que ocupe ese lugar de igualdad permanentemente, con o sin crisis, preferiblemente en todos los momentos sociales incluidos los de mayor bondad social.

Sobre la reflexión de la clase social y de su presencia en la esfera pública, hoy ya no se envía a la hoguera a una mujer por sanadora, porque entre otras cosas ha pasado ya por la Facultad de Medicina correspondiente, ni tiene por qué ocultarse por ello, y la clase social sigue siendo una variable diferenciador muy notable. Los altos cargos políticos o económicos siguen siendo hoy, como en el Imperio Romano, la Edad Media o el siglo XIX, espacio restringidos a las élites, minoritarios por tanto, lo que no permite hablar de una identidad igualitaria en términos democráticos, si bien en el siglo XXI y en el ámbito de la cultura, las mujeres que brillan lo hacen con luz propia y las tabúes van desapareciendo en diversas circunstancias, lo que no impide que, bajo formas aparentemente democráticas a veces, la discriminación y la exclusión persisten en buena medida todavía hoy a pesar de la existencia de un marco legal igualitario. Lo que es innegable es que la mujer está en el proceso de recuperar su identidad sin 
necesidad de ocultarse o protegerse bajo la figura masculina. La mujer ha de conseguir su propia autoestima e identidad a un tiempo, porque ésta es consecuencia de aquélla, lo que permitirá repensar su propia identidad y reconstruirla al fin, de acuerdo con sus propios deseos y una voluntad propia.

Si como se ha señalado, hablar de identidad femenina significa hablar también de identidad masculina, porque ambas son las partes de un mismo constructo social, se puede decir que la mujer ha empezado ya el camino del cambio y va a seguir luchando hasta conseguir una identidad igualitaria, la paridad real, lo que va a requerir la colaboración y la complicidad del hombre y el correspondiente cambio social identitario. Si se pretende llegar a disfrutar de una ética feminista, la identidad femenina ha de ser repensada dentro de un proceso de constitución de las identidades de género en términos sociológicos, esto es, como un proceso históricamente generado que en sí es variable y modificable de acuerdo con la voluntad femenina más progresista. Por tanto, no sólo se debería repensar, sino reconstruir en interacción activa de hombres y mujeres. Ha de surgir un nuevo constructo social (Gómez y Patiño, 2009), que ignore la dicotomía hombre-mujer, donde ambas partes formen un tándem capaz de avanzar en la misma dirección y con el mismo horizonte, donde no subsista ni un solo tabú, ni una sola huella de discriminación negativa y donde ni siquiera aparezca la sospecha que pesa sobre la mujer ante su éxito social incluso en los sectores más progresistas. 


\section{BIBLIOGRAFÍA}

- Aguado, A. M. et al. (1994): Textos para la historia de las mujeres en España, Madrid: Cátedra. - Amorós, C. (1996): "Ética y feminismo". En Enciclopedia Iberoamericana de Filosofía. Cuestiones morales. Madrid: Editorial Trotta/CSIC, pp. 145-171. . (1994): "Igualdad e identidad". En A. Valcárcel (comp.): El concepto de igualdad. Madrid: Ed. Pablo Iglesias, pp. 29-49.

- Bel, M. A. (2000): La Historia de las Mujeres desde los textos, Barcelona: Ariel.

- Bourdieru, P. (2000): La dominación masculina, Barcelona: Anagrama.

- Duby, G. (1992): El amor en la Edad Media y otros ensayos, Madrid: Alianza.

- Durán, M. Á. (2000): Si Aristóteles levantara la cabeza. Quince ensayos sobre las ciencias y las letras. Madrid: Cátedra/ U. Valencia/ Instituto de la Mujer.

- Fray Luis de León (1942): La perfecta casada, Madrid, Edic. Hymsa.

- Freixas, L. (2000): Literatura y Mujeres, Barcelona: Destino.

- Goldmann L. (1967): Para una sociología de la novela, Madrid: Ciencia Nueva.

- Gómez y Patiño, M. (1997): "Las escritoras en lengua alemana”. En Historia y Vida, no. Extraordinario, 1er. Trimestre, pp. 33-41. . (2009): "Mujeres y hombres para la diversidad. Dos componentes de un mismo constructo social”. En P. Nova Melle y J. del Pino Artacho (coords.): Sociedad y Tecnología: ¿Qué futuro nos espera?, pp. 29-36.

- Lemert, E. (1972): Human deviance. Social Problem \& Social Control, N. York: Englewood Cliffs, Prentice-Hall.

- Lukacs, G. (1916): Teoría de la novela, Madrid: Editora Nacional.

- Martínez, C. (1994): "Introducción a Aguado, A. M". En: Aguado, A. M. et al. (1994): Textos para la historia de las mujeres en España, Madrid: Cátedra, pp. 29-39.

- Pardo Bazán, E. (1999): La mujer española y otros escritos, Madrid: Cátedra/Universitat de València/Instituto de la Mujer.

- Radl Philipp, R. M. ( coord.) (1996): "Los procesos de la constitución social de las identidades de género en el contexto de la socialización humana: bases para un modelo teóricointeraccionista”. En Mujeres e Institución Universitaria en Occidente. Conocimiento, investigación y roles de género. Santiago de Compostela: Universidad, pp. 15-37.

- Solé, R. (1988): “Arraigo y desarrollo de la conciencia feminista”, En: Historia-16, no. 145, mayo: 80-85.

- Wright, E. R.; Gronfein, W. P. y Owens, T. J. (2000): "Deinstitutionalization, Social Rejection, and the Self-Esteem of Former Mental Patients". En Journal of Health and Social Behavior, Vol. 41, mar, pp. 68-90. 